\title{
Maternal effects and changing phenology of bird migration
}

\author{
Anders Pape Møller ${ }^{1, *}$, Clotilde Biard ${ }^{2}$, Filiz Karadas ${ }^{3}$, Diego Rubolini ${ }^{4}$, \\ Nicola Saino ${ }^{4}$, Peter F. Surai ${ }^{5}$ \\ ${ }^{1}$ Laboratoire d'Ecologie, Systématique et Evolution, CNRS UMR 8079, Université Paris-Sud, Bâtiment 362, \\ 91405 Orsay Cedex, France \\ ${ }^{2}$ UPMC Paris 06, CNRS UMR 7625, Laboratoire Ecologie-Evolution, 75252 Paris Cedex 05, France \\ ${ }^{3}$ University of Yuzuncu Yil, Department of Animal Science, 65980 Van, Turkey \\ ${ }^{4}$ Dipartimento di Biologia, Università degli Studi di Milano,Via Celoria 26, 20133 Milano, Italy \\ ${ }^{5}$ Department of Biochemistry and Nutrition, Avian Science Research Centre, Scottish Agricultural College, Ayr KA6 5HW, UK
}

\begin{abstract}
Recent changes in migration distances and propensity for migration associated with climate change have suggested that these traits can evolve rapidly. Part of this rapid response to selection may be due to maternal effects that facilitate changes in the underlying physiology of migration. We hypothesize that exposure to large amounts of antioxidants in the egg will facilitate assimilation and metabolism of dietary antioxidants later in life, thereby allowing offspring to better cope with extreme strenuous exercise such as the bursts of rapid migration shown during spring migration. We tested the relationship between temporal change in mean arrival date of migratory birds since 1960 and concentrations of 2 antioxidants in the eggs of 14 species of birds. Only egg concentration of vitamin $\mathrm{E}$ was a significant predictor of advancement in spring arrival date. Furthermore, we experimentally manipulated egg content of vitamin $\mathrm{E}$ in barn swallows Hirundo rustica and subsequently recorded arrival date of yearling male recruits. Arrival date advanced significantly by $>1$ standard deviation due to treatment, providing experimental evidence for a relationship between egg concentration of vitamin $E$ and subsequent migration behavior. These results are consistent with the hypothesis that maternal effects have played an important role in the evolution of bird migration.
\end{abstract}

KEY WORDS: Maternal effects $\cdot$ Phenology $\cdot$ Phenotypic plasticity $\cdot$ Vitamin A $\cdot$ Vitamin E

\section{INTRODUCTION}

Migratory birds visit all parts of the world during their annual migrations between breeding and wintering grounds, and they are thereby able to exploit favorable conditions at different sites at different times of the year (Berthold 2001). This ability comes at the viability cost of annual migrations. Therefore, the evolution of migration in birds (and other organisms) can be used as a model system for the study of how immediate fitness benefits are traded against costs of twice-annual bouts of extreme exercise.
Bird migration entails strenuous exercise often over extreme distances, and many physiological adaptations to bird migration have been described. Physical activity is associated with the production of free radicals that are potentially harmful to DNA and other molecules. Antioxidants such as carotenoids and vitamins A and E have the capability of neutralizing free radicals (e. g. Møller et al. 2001, Surai 2002), and migratory birds would therefore be expected to ingest more antioxidants than residents in response to elevated free radical levels as a result of higher levels of physical activity (Ninni et al. 2004, Costantini et al. 2007). In addition, antioxidant levels 
should be depleted at arrival after spring migration, and vary among individuals differing in timing of spring arrival, as described for the barn swallow Hirundo rustica (Ninni et al. 2004).

Bird migration can change rapidly, as shown by selection experiments (review in Pulido \& Berthold 2004). Recent rapid climate change has caused arrival dates of many different migratory bird species to advance, although effects are heterogeneous among species (reviews in Lehikoinen et al. 2004, Rubolini et al. 2007, Lehikoinen \& Sparks 2010). Thus, rapid evolutionary or phenotypically plastic change is possible, although the underlying mechanisms remain to be determined. Many studies have shown a strong additive genetic component to migratory variables (review in Pulido \& Berthold 2004), suggesting that the genetic precondition for microevolutionary change is present. Likewise, numerous studies have shown persistent strong selection for early arrival (review in Pulido \& Berthold 2004), implying that a response to selection would be expected, provided that the quantitative genetic estimates are unbiased and that strong negative genetic correlations do not prevent responses (Møller \& Merilä 2004). The complicating role of maternal effects has rarely been addressed (for the only exception see Pulido \& Berthold 2010). Maternal effects arise from the direct effects of the mother (or the father) on the phenotype of offspring, and they can have significant effects on the rate and direction of evolution (Mousseau \& Fox 1998). Maternal effects may play a role in evolutionary change (Mousseau \& Fox 1998, Badyaev \& Uller 2009). If maternal effects act in the same direction as selection, (e.g. because warmer springs favor early spring arrival of migrants as well as earlier and more abundant emergence of insect food), maternal effects can speed up the rate of evolution, while oppositely directed effects will slow down the rate of evolution. Thus, maternal effects would in the first case further advance spring arrival beyond what is accounted for by micro-evolution, while maternal effects in the second scenario would reduce the environmental component of spring arrival date and hence slow down the apparent rate of evolution.

Maternal effects are widely known as parental mediators of offspring phenotype, often in an adaptive way (e. g. Mousseau \& Fox 1998). Such effects can also have important priming impacts on the ability later in life to respond to exposure to similar biochemical substances as those involved in the maternal effect. For example, early exposure to carotenoids during embryonic development can affect the ability to assimilate or metabolize carotenoids and hence utilize these later in life, while individuals without such early exposure or with weaker exposure demonstrate reduced assimilation and metabolism abilities (Hõrak et al. 2000, Koutsos et al. 2003). Furthermore, early stressful conditions for the offspring can later affect the ability to produce maternal effects, potentially providing a link between environmental conditions and the subsequent ability to modify offspring phenotype (Gil et al. 2004). Thus, maternal effects may affect the ability of offspring later in life to exploit particular biochemicals, but also to respond to these and produce substances that may facilitate specific physiological mechanisms.

Here we suggest that maternal effects may play a hitherto unrecognized role in the evolution of bird migration by: (1) affecting the ability of individuals to withstand the physiological costs of migration and (2) by facilitating the evolution of rapid change. Hypothesis (1) proposes that maternal effects improve the ability of offspring later in life to metabolize, exploit and utilize antioxidants. We carried out a preliminary test of this hypothesis by relating the rate of recent change in spring arrival dates of different migratory bird species (Rubolini et al. 2007) to the amount of maternal antioxidants allocated to eggs in these same species. Thus, we tested the hypothesis that early exposure to antioxidants will facilitate the ability to withstand and cope with the extreme bursts of free radical production associated with migration (Costantini et al. 2007). Therefore, individuals with high exposure to maternal antioxidants in the egg would be able to cope with particularly strenuous exercise, such as spring migration, in order to arrive at breeding grounds early. Early exposure to antioxidants has the effect of increasing the bird's future ability to absorb, metabolize and use antioxidants. Clearly, migratory birds would benefit from increased levels of antioxidants in general, and vitamin $\mathrm{E}$ in particular, even in the absence of climate change. However, assuming that antioxidant provision at the egg stage has an influence on metabolism during extreme exercise later in the bird's life, there is every reason to believe that individuals will differ in their assimilation and metabolism abilities even in the absence of climate change, because mothers, by default, differ in their abilities to provision their eggs. This effect may arise from a trade-off between egg quality and self-maintenance, with mothers in poor condition allocating smaller quantities of antioxidants to their eggs. Indeed, when antioxidants are limiting, females may not produce eggs (Møller et al. 2005), or produce fewer eggs of poorer quality (Blount et al. 2002). Thus, such females may produce 
offspring with a poor ability to manage their antioxidant status during rapid spring migration. There is also evidence showing that the response in terms of laying date and, hence, most likely also spring arrival date (Saino et al. 2004) to climate change is stronger in birds in prime condition (Møller 2008).

Subsequently, we carried out a preliminary test of the Hypothesis 2, by investigating whether arrival date can be affected by embryo exposure to maternal antioxidants. More specifically, we tested the prediction that experimental manipulation of the vitamin $\mathrm{E}$ content of eggs advanced the subsequent spring arrival date of individuals produced from such eggs compared to controls. This experiment mimicked the situation in which a mother allocated more (treatment group) or less vitamin E (control group) to their eggs. Although different kinds of maternal effects are often treated as independent in intraspecific and interspecific studies, different maternal antioxidant effects show significant correlations, implying that the function of a given maternal effect cannot be deduced without controlling statistically (or experimentally) for the correlated effects of other antioxidants. Therefore, we analyzed the combined and independent effect of 2 different maternal effects (vitamins A and E). Finally, bird migration constitutes a 'syndrome' with many different traits apparently coevolving. This implies that even if a positive association is found between bird migration and maternal effects, we must control statistically for other factors that are also correlated with bird migration. Here we adjusted for the fact that sexual selection and bird migration show positive covariation, as demonstrated by the positive association between incidence and length of bird migration and indices of the strength of sexual selection, including plumage dichromatism in birds (Fitzpatrick 1994), rates of extra-pair paternity (Spottiswoode \& Møller 2004), and levels of song complexity (Read \& Weary 1992, Mountjoy \& Leger 2001). However, sexual dichromatism is not linked to levels of egg antioxidants (Biard et al. 2009). We tested these predictions by investigating phylogenetic correlations after accounting for similarity in phenotype among species due to common descent.

\section{MATERIALS AND METHODS}

\subsection{Samples}

With the help of colleagues and under permit from the relevant conservation authorities, we collected fresh eggs during the breeding seasons from 2000 to
2003 from clutches of birds that had not been incubated. For ethical reasons we restricted the number of clutches to a minimum that would allow quantification of the amount of variance within and among species. We obtained samples for 93 species (Biard et al. 2009), leaving 14 species for which we had information on both maternal antioxidant egg components and information on change in spring arrival date, the remaining species being residents, or there was no information on the change in their spring arrival date.

\subsection{Change in timing of spring migration}

We used an extensive data set on temporal change in mean or median arrival date of migratory birds from Europe (Rubolini et al. 2007). This data set consists of 672 estimates of change in arrival date with a minimum duration of $15 \mathrm{yr}$, collected between 1960 and 2006. We calculated least square mean change in arrival date, after controlling for the effects of longitude and initial year of time series, as reported by Rubolini et al. (2007, their Table 3).

\subsection{Experimental manipulation of vitamin $\mathbf{E}$ content of eggs, and determination of arrival date}

We injected eggs with vitamin $\mathrm{E}$ or a control substance, using a technique developed by Saino et al. (2003). Barn swallow Hirundo rustica eggs contain, according to our own analyses, $97.97 \mu \mathrm{g}$ vitamin $\mathrm{E}$ $\mathrm{g}^{-1}(\mathrm{SD}=22.41, \mathrm{CV}=29 \%, \mathrm{~N}=5)$, with $94.00 \mu \mathrm{g} \mathrm{g}^{-1}$ being $\alpha$-tocopherol and the rest being $\gamma$-tocopherol. Nests were checked daily for laying to ensure that manipulations were conducted at the same stage of reproduction. This procedure also allowed for determination of laying date and clutch size. In brief, A. P. Møller injected 182 clutches (88 in 2005 and 94 in 2006) of barn swallows containing 705 eggs (334 in 2005 and 371 in 2006) at Kraghede, Denmark, randomly with either $22 \mu \mathrm{g}$ of vitamin E ( $\alpha$-tocopherol) diluted in $5 \mu$ l of corn oil or $5 \mu$ l of corn oil only (control treatment) during the breeding seasons from 2005 to 2006. This dose increased the concentration of vitamin $\mathrm{E}$ in eggs by ca. $2 \mathrm{SD}$, assuming a yolk mass of ca. $0.5 \mathrm{~g}$ (A. P. Møller unpubl. data), within the normal range of vitamin $\mathrm{E}$ in the population. We note that corn oil contains small amounts of vitamin $\mathrm{E}$, with concentrations in the range of from 1.25 to $2.25 \mu \mathrm{g}$ in $5 \mu \mathrm{l}$. Thus, the amount injected in the vitamin E treatment $(22 \mu \mathrm{g}+1.75 \mu \mathrm{g}=23.75 \mu \mathrm{g})$ was more than an order of magnitude higher than in the control 
treatment $(1.75 \mu \mathrm{g})$. Injection followed disinfection of the eggshell, with the hole being sealed with superglue and a small piece of swallow eggshell superimposed. All eggs were injected the day following the laying date. Hatching success of eggs from the 2 treatments was $88.9 \%$ from vitamin E injected eggs $(\mathrm{N}=351)$ and $89.5 \%$ from control injected eggs $(\mathrm{N}=$ 353). These rates are similar to the hatching success of $89.2 \%$ of 3128 first clutches from this population during the period from 1984 to 2008 (A. P. Møller unpubl. data). All nestlings were ringed at ca. $12 \mathrm{~d}$ old.

Arrival date of barn swallows was recorded in 2006 and 2007 by 3 times weekly capture sessions at all breeding sites within the study area between May and June. Previous studies of the barn swallows have shown that this procedure provides reliable information on arrival date, as revealed by independent estimates of arrival date using observations of color ringed birds (Møller et al. 2004).

\subsection{Antioxidant analyses}

Eggs were separated into egg white and yolk, and the yolk was used for antioxidant analyses. Both components of the eggs were frozen as soon as possible after collection (usually within $1 \mathrm{~d}$ ) and always immediately after separation, and then maintained at $-20^{\circ} \mathrm{C}$ until analysis. Antioxidants were extracted from eggs using 0.1 to $0.2 \mathrm{~g}$ of yolk. Samples were homogenized with $0.7 \mathrm{ml} \mathrm{NaCl}(5 \%)$ and $1 \mathrm{ml}$ ethanol, after which antioxidants were extracted adding $2 \mathrm{ml}$ hexane and further homogenization, centrifugation and collection of the hexane phase (extraction repeated twice). Hexane extracts were pooled and evaporated at 60 to $65^{\circ} \mathrm{C}$ under nitrogen flow, and the residue was then dissolved in $0.1 \mathrm{ml}$ dichloromethane and $0.1 \mathrm{ml}$ methanol. Vitamin E and A concentrations were determined following previously published procedures (Hõrak et al. 2002, Surai 2002). Concentrations of vitamins $\mathrm{E}$ and A were determined by injection of samples onto a Spherisorb type ODS2 $3-\mu$ C18 reverse-phase column, $15 \mathrm{~cm} \times 4.6 \mathrm{~mm}$ (Phase Separation) with a mobile phase of methanol/ distilled water (97:3), at a flow rate of $1.05 \mathrm{ml} \mathrm{min}^{-1}$ using fluorescence detection by excitation and emission wavelengths, respectively, of 295 and $330 \mathrm{~nm}$ for vitamin E and 330 and $480 \mathrm{~nm}$ for vitamin A. Peaks of $\delta$-, $\gamma$ - and $\alpha$-tocopherol were identified by comparison with the retention time of standards of tocopherols (Sigma). All sampled eggs were analyzed for vitamin $\mathrm{E}$ and vitamin A concentrations. Vitamin $\mathrm{E}$ was calculated as the summed concentrations of $\delta$-, $\gamma$ - and $\alpha$-tocopherol. Concentration and not quantity of vitamins $\mathrm{E}$ and $\mathrm{A}$ was used as the variable of interest in statistical analysis because concentration is the main factor in determining the physiological action of antioxidants at the level of tissues (Surai 2002). The inter-assay coefficient of variation for $\alpha$-tocopherol determination was $3.9 \%$ (Surai et al. 2000). There was significantly more variation among than within species in vitamin E (Biard et al. 2009). Only mean $( \pm \mathrm{SE})$ vitamin $\mathrm{E}$ and vitamin A concentrations were available for Corvus corone, and sample size for Acrocephalus palustris was 1 egg, hence 13 species were left for repeatability analysis of the contents of vitamins $\mathrm{E}$ and $\mathrm{A}$ in eggs.

\subsection{Confounding variables}

Comparative analyses necessitate the investigation of any potentially confounding variables that might generate a spurious association.

Sexual dichromatism is related to the evolution of bird migration (Fitzpatrick 1994), and thus we included this variable in the statistical analyses. We scored the breeding plumage of all species as sexually monochromatic if males and females did not differ in coloration according to descriptions provided in the series of publications by Cramp \& Perrins (1977 to 1994), and otherwise as sexually dichromatic.

We estimated migration distance as the difference in latitude between the mean of the northernmost and the southernmost breeding distribution and the mean of the northernmost and the southernmost winter distribution, relying on information from Cramp \& Perrins (1977 to 1994).

Body mass of birds during the breeding season was also obtained from Cramp \& Perrins (1977 to 1994).

Mean $( \pm \mathrm{SE})$ concentrations $\left(\mu \mathrm{g} \mathrm{g}^{-1}\right)$ and information on confounding variables for each species are given in Table A1 in the Appendix.

\subsection{Comparative analyses}

Comparative analyses of biological information must take the phylogenetic relationships among taxa into account in order to control for statistical dependence in the data. We calculated statistically independent linear contrasts that are based on standardized differences in phenotypic values among taxa rather than the species-specific phenotypic values themselves (Felsenstein 1985), using the software CAIC developed by Purvis \& Rambaut (1995). Standardiza- 
tion of contrast values was checked by examination of absolute values of standardized contrasts versus their standard deviations (Garland 1992, Garland et al. 1992). Plotting the resulting contrasts against the variances of the corresponding nodes revealed that these transformations made migration distance unsuitable for regression analyses because of 4 outlier contrasts (contrasts with Studentized residuals $>3$ ). We explicitly tested for this problem of heterogeneity in variance by excluding outliers from analyses (see Jones \& Purvis 1997), although that did not affect the conclusions. If we used an alternative approach based on generalized least squares models (Pagel 1997, 1999), which requires fewer assumptions, the results were very similar to those reported below.

We developed a composite phylogeny for the species based on information in Sibley \& Ahlquist (1990) to resolve relationships between species (Fig. A1 in the Appendix). We applied branch lengths from the phylogeny of Sibley \& Ahlquist (1990) for higher taxonomic levels.

All statistical analyses of the linear contrasts were made with JMP (2000). Prior to phylogenetic analyses, we $\log _{10}$-transformed maternal effects and body mass. We treated sexual dichromatism as a continuous variable despite it being dichotomous, which is a similar approach to the use of dummy variables in regression analyses. Contrasts were analyzed using regression forced through the origin, because when the independent variable has not changed (i.e. there has been no evolutionary change in the independent variable), we should not expect an evolutionary change in the dependent variable due to the independent variable (Purvis \& Rambaut 1995). We deleted predictor variables to reduce the statistical model to one with a minimum number of variables. This analysis was based on elimination of variables that were not significant ( $p>0.05)$. We removed non-significant variables, but the removed terms were re-entered to the final model one by one to obtain the corresponding statistics. Because maternal effects were quantified as concentrations, we included body mass as a covariate in all analyses in order to control for differences in body size and hence egg size among species (for information on the tight correlation between egg mass and body mass see Bennett \& Owens 2002).

Sample sizes differed among species in the comparative analysis, as is commonly the case (Garamszegi \& Møller 2010). We adjusted for sample size by weighting the analyses by $\log _{10}$-transformed sample size to avoid putting undue weight on the 2 species with very large sample sizes (for justification see Garamszegi \& Møller 2010).

\section{RESULTS}

\subsection{Change in timing of migration, and maternal effects}

Temporal change in arrival date was predicted by vitamin E concentration in eggs (Fig. $1 ; F_{1,12}=14.56$, $\mathrm{df}=1,12, \mathrm{r}^{2}=0.55, \mathrm{p}=0.0025$, slope $=-0.390 \pm$ 0.102 [ \pm SE here and below in body text]). An analysis based on ranks gave similar results $\left(F_{1,12}=7.67, \mathrm{r}^{2}=\right.$ $0.39, \mathrm{p}=0.017$, slope $=-0.648 \pm 0.234)$. In contrast, there was no similar effect of vitamin $\mathrm{A}$, which is the other major fat-soluble antioxidant $\left(F_{1,12}=0.20, \mathrm{r}^{2}=\right.$ $0.02, \mathrm{p}=0.66)$. An analysis of independent contrasts for vitamin $E$ provided similar conclusions $\left(F_{1,12}=\right.$ $7.34, \mathrm{p}=0.019$, slope $=-0.341 \pm 0.126)$, even when using ranks $\left(F_{1,12}=6.50, \mathrm{r}^{2}=0.35, \mathrm{p}=0.024\right.$, slope $=$ $-0.577 \pm 0.226)$. Vitamin $E$ was retained in the final model (Table 1), with no confounding effect of sexual dichromatism (analysis of species-specific values in a model that included both vitamin $E$ and sexual dichromatism as predictors: $F_{1,11}=0.02, \mathrm{r}^{2}=0.00, \mathrm{p}=$ 0.90 , slope $=0.006 \pm 0.045 ;$ contrasts: $F_{1,11}=0.02, \mathrm{p}=$ 0.90 , slope $=-0.006 \pm 0.052$ ). Finally, migration distance did not significantly predict change in arrival date when entered together with vitamin $\mathrm{E}$ (analysis of species-specific values in a model that included both vitamin $\mathrm{E}$ and migration distance as predictors: $F_{1,11}=0.52, \mathrm{r}^{2}=0.05, \mathrm{p}=0.49$, slope $=0.027 \pm 0.038$; contrasts: $F_{1,11}=0.38, \mathrm{p}=0.55$, slope $=0.031 \pm 0.051$ ).

Finally, we tested if sample size affected the conclusions by weighting the comparative analysis by $\log _{10}$-transformed stample size. The negative relationship between change in arrival date and concentration of vitamin E was qualitatively similar to the unweighted analysis $\left(F_{1,12}=10.33, \mathrm{p}=0.0074\right.$, slope $=$ b-0.375 \pm 0.117 ).

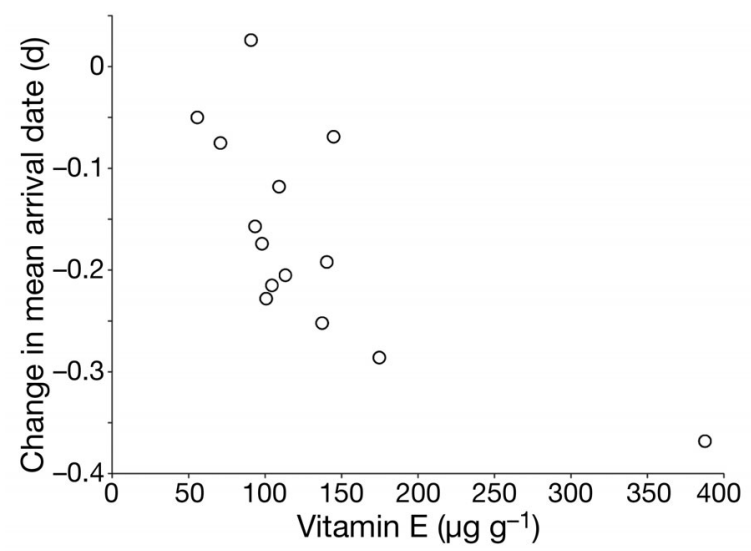

Fig. 1. Relationship between change in mean spring arrival date in Europe and concentration of vitamin $\mathrm{E}$ in eggs $\left(\mu \mathrm{g} \mathrm{g}^{-1}\right)$ among species of birds 
Table 1. Relationship between rate of temporal change in mean arrival date of migratory birds and vitamin E concentration in their eggs. Analyses are based on species-specific values and statistically independent linear contrasts, respectively

\begin{tabular}{|lccccc|}
\hline Models & Sum of squares & df & $F$ & $p$ & Slope \pm SE \\
\hline Species & & & & & \\
Vitamin E & 0.078 & 1 & 14.56 & 0.0025 & $-0.390 \pm 0.102$ \\
Error & 0.064 & 12 & & & \\
Contrasts & & 1 & 9.51 & 0.0087 & $-0.410 \pm 0.133$ \\
Vitamin E & 0.021 & 12 & & & \\
Error & 0.029 & 129 & & & \\
\hline
\end{tabular}

\subsection{Manipulation of egg vitamin E content and effect on arrival date}

The experiment resulted in recruitment of 24 yearling male barn swallows into the study population (11 experimentals [5 from 2005 and 6 from 2006] and 13 controls [6 from 2005 and 7 from 2006]), while the 4 recruiting females precluded meaningful analysis of that sex. There was a significant effect of treatment on arrival date, explaining $36 \%$ of the variance $\left(F_{1,22}=12.34, \mathrm{r}^{2}=0.36, \mathrm{p}=0.0020\right)$. The statistical power of this test was 0.86 for a significance level of $5 \%$. Treated eggs produced male recruits that arrived, on average, $10 \mathrm{~d}$ earlier than controls, or 1.6 standard deviations (Fig. 2). There were no additional unintended effects of laying date or clutch size on arrival date (laying date: $F_{1,20}=0.71, \mathrm{p}=0.41$; clutch size: $F_{1,20}=0.26, \mathrm{p}=0.62$ ). Body mass was slightly larger in vitamin E-treated birds than in con-

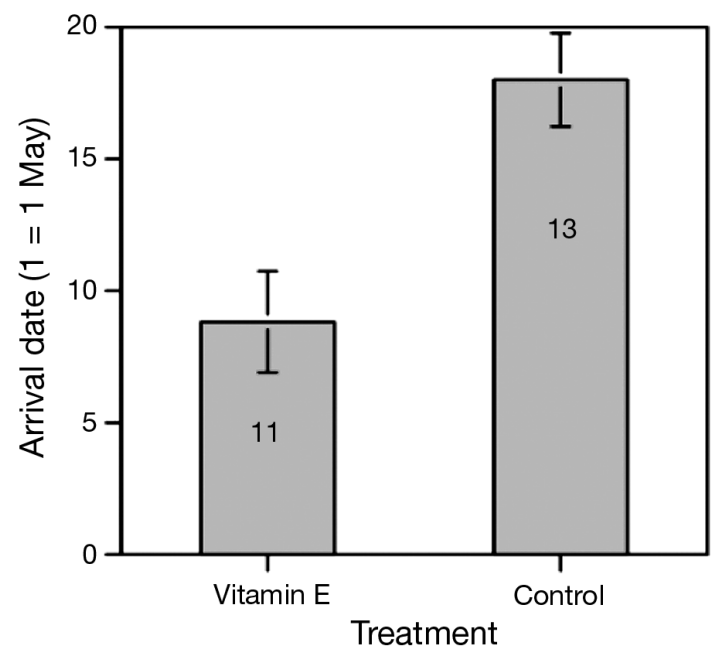

Fig. 2. Hirundo rustica. Relationship between arrival date (mean $\pm \mathrm{SE}$; 1 : May 1st) of yearling male barn swallows and experimental treatment of the eggs from which they hatched. Eggs were either injected with extra vitamin E or a control substance. Numbers are sample sizes trols $\left(F_{1,22}=5.06, \mathrm{r}^{2}=0.19, \mathrm{p}=0.035\right.$ mean vitamin E: $19.7 \mathrm{~g} \pm 0.3$; controls: $18.7 \mathrm{~g} \pm 0.3$ ), but the effect of body mass on arrival date was not statistically significant $\left(F_{1,21}=0.42, \mathrm{p}=0.52\right)$.

The combined probability of the 2 independent tests of the hypothesis that maternal effects affected spring arrival (the interspecific comparative analysis and the intraspecific experiment) was $\chi^{2}=12.20, \mathrm{df}=4, \mathrm{p}<$ 0.0001 .

\section{DISCUSSION}

The main findings of the present study were that: (1) bird species with high concentrations of vitamin $\mathrm{E}$ in their eggs advanced their spring arrival dates more than species with low concentrations and (2) male barn swallows Hirundo rustica hatched from eggs supplemented with extra vitamin E arrived earlier from spring migration than males hatched from control eggs. These findings are consistent with the hypothesis that maternal effects affect response to climate change. Pulido \& Berthold (2010) have recently shown that the onset of migratory activity in autumn by blackcaps Sylvia atricapilla has a significant maternal component, although this effect has not changed significantly during recent years as migration has advanced.

Vitamin E concentration in birds' eggs, but not vitamin A concentration, was significantly positively related to advancement in spring arrival date across species. This result was obtained for species with migratory distances ranging from short-distance migrants like blue tits Parus caeruleus that are only migratory in the northern parts of their breeding range to the marsh warbler Acrocephalus palustris that migrates over $>65^{\circ}$ of latitude. We controlled statistically for all known potentially confounding variables that have been shown to correlate with migration and antioxidant concentration of eggs. Vitamin E has an antioxidant role that is of vital importance for developing embryos and young birds, which are subject to increased oxidative stress as a by-product of metabolism associated with rapid development (Blount et al. 2000, Surai 2002, Blount 2004). Oxidative stress by free radicals can be linked to changes in the development of muscle and brain tissues that are the engines and coordinators of strenuous longdistance flight. Alternatively, early maternal effects may affect the ability to acquire and transform 
dietary antioxidants, with consequences for the ability of such birds to cope with oxidative stress later in life. Hence, if antioxidants do help birds avoid the harmful consequences of oxidative stress, this may set the scene for coevolution between traits related to migration and maternally derived antioxidants deposited in the egg. In fact, vitamin $\mathrm{E}$ is particularly effective as a biological antioxidant; markedly ameliorating the effect of oxidative stress (Hartley \& Kennedy 2004); it is also the main antioxidant in biological membranes. Furthermore, vitamin E concentration can vary greatly among species (Biard et al. 2009), and there is no risk of vitamin E overdose (Surai 2002). Vitamin $E$ is widely distributed in nature and birds can use various sources of this vitamin to build up reserves in tissues. It seems likely that vitamin $\mathrm{E}$ is involved in regulation of the redox status of the cell, leading to changes in gene expression (Surai 2002). In the body, vitamin $E$ can be accumulated in the fat tissue (Surai 2002) that is a source of energy for migrating birds.

While the comparative analyses were consistent with our working hypothesis that maternal effects have played a role in the evolution of arrival date, the field experiment that increased the level of vitamin $\mathrm{E}$ in certain eggs provided direct evidence for a causal relationship between antioxidant levels and arrival date. The underlying assumption of this experiment is that mothers can actively regulate the transfer of vitamin $\mathrm{E}$ to their eggs in response to environmental stimuli. Although there is no direct evidence regarding vitamin $\mathrm{E}$, female barn swallows have been shown to modify their allocation of carotenoids to their eggs depending on the sexual attractiveness of their mates, suggesting that there is considerable flexibility in such allocation rules of antioxidants in this species (Saino et al. 2002). As de Ayala et al. (2006) have previously shown for barn swallows, dietary supplementation with vitamin $\mathrm{E}$ enhances growth and body condition of nestlings. Here, we have shown that male barn swallows hatched from eggs injected with extra vitamin E arrived significantly earlier than males hatched from control eggs. The advancement of spring arrival date was on average $10 \mathrm{~d}$, or $>1.6$ standard deviations, which by any measure must be considered a large effect. Final sample size was only 24 male recruits, although $>700$ eggs were originally injected. This poor outcome was due to the fact that dispersal is generally extensive in migratory birds (Paradis et al. 1998, Belliure et al. 2000). Previous studies of barn swallows have documented a local recruitment rate within our study population of $2.0 \%$ during a period of 22 yr (Balbontín et al. 2009), similar to the rate reported here. However, it is unlikely that this can have caused any bias in the conclusions. For example, clutch size and breeding date did not differ significantly between recruits derived from the 2 treatments, and we are unaware of any other potentially confounding variable due to vitamin $\mathrm{E}$ treatment that could have affected the results.

Our hypotheses suggest that maternal effects may play a role in the evolution of bird migration: (1) by mitigating migration costs and (2) by permitting rapid change in migratory phenology. The empirical findings that we report are consistent with these hypotheses, and explicitly narrow the field of such maternal effects down to antioxidants, suggesting a mechanistic role for vitamin $\mathrm{E}$ in the evolution of arrival date. This may arise from short-term effects during embryonic development, or from long-lasting embryonic effects acting in adulthood. According to the first mechanism, mothers of long-distance migrants may deposit more vitamin E into the egg in order to eliminate oxidative stress due to free radicals that rapidly growing muscle tissues produce (Surai 2002). Because changing climate will affect the phenology and abundance of insect food, egg composition may change directly in response to changing climatic conditions (for such an effect in 2 other maternal egg components see Saino et al. 2004). The antioxidant function of vitamin $\mathrm{E}$ may be important for the developing brain, which is extremely sensitive to oxidative stress (Connor \& Menzies 1995, Surai et al. 1996, Noseworthy \& Bray 1998, Tyurin et al. 2000, Butterfield 2002, Hilscherova et al. 2003), but will later be responsible for the neural governing of migration (Healy et al. 1991, 1996, Winkler et al. 2004). Alternatively, prenatal exposure to high levels of vitamin E may have consequences in adults for the assimilation and metabolism of an entire set of biological molecules that prevent the physiological costs of migration. For example, migration involves costs due to oxidative stress (Welker \& Congleton 2005), a higher risk of being parasitized (Møller \& Erritzøe 1998, Waldenström et al. 2002) or infection by viral, bacterial and fungal pathogens (Hubálek 2004), and costs due to physiological needs (Battley et al. 2001). If maternally transmitted vitamin $\mathrm{E}$ facilitates the metabolism of molecules that contribute to the physiological adaptation to long-distance flight, selection arising from migration will favor increased yolk levels of vitamin E.

We investigated the potentially confounding effects of sexual dichromatism on the relationship between vitamin $\mathrm{E}$ and migration distance, but found no evidence that this variable had been involved in 
producing a spurious correlation. Obviously, other potentially confounding variables could be involved, although we are unaware of any such effects having been reported in the literature.

Phenological change may either arise as a consequence of phenotypic plasticity or evolutionary change (Møller \& Merilä 2004, Pulido \& Berthold 2004). The distinction between these 2 alternatives requires genetic analyses either from breeding experiments or the field, as reported by Pulido \& Berthold (2010). While the present study does not resolve to what extent phenological change is caused by phenotypic plasticity or evolutionary change, it does have implications for this discussion. In particular, we emphasize that phenotypic change linked to maternal effects requires fewer assumptions than change due to a micro-evolutionary response to selection (the mechanism that involves fewer assumptions is more likely, as stated by Occam's razor). Such change can also be much more rapid than evolutionary change, and continued change over long time periods due to maternal effects does not rely on similarly strict assumptions as changes caused by evolutionary responses to selection.

In conclusion, species of birds that have shown the greatest changes in timing of migration during recent changes in climate had elevated concentrations of vitamin $\mathrm{E}$ in their eggs. Furthermore, male barn swallows produced from eggs with experimentally elevated levels of vitamin E arrived earlier than controls, providing experimental evidence for an effect of antioxidants on migration. These findings have implications for the evolution of bird migration and for maternal allocation strategies to eggs.

Acknowledgements. Prof. E. Lehikoinen helped collect the phenology database.

\section{LITERATURE CITED}

Badyaev AV, Uller T (2009) Parental effects in ecology and evolution: mechanisms, processes and implications. Philos Trans R Soc B 364:1169-1177

Balbontín J, Møller AP, Hermosell IG, Marzal A, Reviriego M, de Lope F (2009) Divergent patterns of impact of environmental conditions on life history traits in two populations of a long-distance migratory bird. Oecologia 159: 859-872

Battley PF, Dietz MW, Piersma T, Dekinga A, Tang SX, Hulsman K (2001) Is long-distance bird flight equivalent to a high-energy fast? Body composition changes in freely migrating and captive fasting great knots. Physiol Biochem Zool 74:435-449

Belliure J, Sorci G, Møller AP, Clobert J (2000) Dispersal distances predict subspecies richness in birds. J Evol Biol 13:480-487
Bennett PM, Owens IPF (2002) Evolutionary ecology of birds. Oxford University Press, Oxford

Berthold P (2001) Bird migration. Oxford University Press, Oxford

> Biard C, Gil D, Karadas F, Saino N, Spottiswoode C, Surai PF, Møller AP (2009) Maternal effects mediated by antioxidants and the evolution of carotenoid-based signals in birds. Am Nat 174:696-708

> Blount JD (2004) Carotenoids and life-history evolution in animals. Arch Biochem Biophys 430:10-15

$>$ Blount JD, Houston DC, Møller AP (2000) Why egg yolk is yellow. Trends Ecol Evol 15:47-49

> Blount JD, Surai PF, Nager RG, Houston DC, Møller AP, Trewby ML, Kennedy MW (2002) Carotenoids and egg quality in the lesser black-backed gull (Larus fuscus): a supplemental feeding study of maternal effects. Proc Biol Sci 269:29-36

Butterfield DA (2002) Amyloid beta-peptide (1-42)-induced oxidative stress and neurotoxicity: implications for neurodegeneration in Alzheimer's disease brain. A review. Free Radic Res 36:1307-1313

> Connor JR, Menzies SL (1995) Cellular management of iron in the brain. J Neurol Sci 134:33-44

> Costantini D, Cardinale M, Carere C (2007) Oxidative damage and anti-oxidant capacity in two migratory bird species at a stop-over site. Comp Biochem Physiol C Toxicol Pharmacol 144:363-371

Cramp S, Perrins CM (eds) (1977-1994) The birds of the western Palearctic, Vols 1-9. Oxford University Press, Oxford

de Ayala RM, Martinelli R, Saino N (2006) Vitamin E supplementation enhances growth and condition of nestling barn swallows (Hirundo rustica). Behav Ecol Sociobiol 60:619-630

Felsenstein J (1985) Phylogenies and the comparative method. Am Nat 125:1-15

Fitzpatrick S (1994) Colorful migratory birds-evidence for a mechanism other than parasite resistance for the maintenance of good genes. Proc Biol Sci 257:155-160

Garamszegi LZ, Møller AP (2010) Effects of sample size and intraspecific variation in phylogenetic comparative studies: a meta-analytic review. Biol Rev Camb Philos Soc 85: 797-805

Garland Jr T (1992) Rate tests for phenotypic evolution using phylogenetically independent contrasts. Am Nat 140: 509-519

Garland T, Harvey PH, Ives AR (1992) Procedures for the analysis of comparative data using phylogenetically independent contrasts. Syst Biol 41:18-32

Gil D, Heim E, Bulmer E, Rocha M, Puerta M, Naguib M (2004) Negative effects of early developmental stress on adult yolk testosterone levels in a passerine bird. J Exp Biol 207:2215-2220

> Hartley RC, Kennedy MW (2004) Are carotenoids a red herring in sexual display? Trends Ecol Evol 19:353-354

> Healy SD, Krebs JR, Gwinner E (1991) Hippocampal volume and migration in passerine birds. Naturwissenschaften 78:424-426

> Healy SD, Gwinner E, Krebs JR (1996) Hippocampal volume in migratory and non-migratory warblers: effect of age and experience. Behav Brain Res 81:61-68

Hilscherova K, Blankenship AL, Nie M, Coady KK, Upham BL, Trosko JE, Giesy JP (2003) Oxidative stress in liver and brain of the hatchling chicken (Gallus domesticus) following in ovo injection with TCDD. Comp Biochem Physiol C Toxicol Pharmacol 136:29-45

> Hõrak P, Vellau H, Ots I, Møller AP (2000) Growth condi- 
tions affect carotenoid-based plumage coloration of great tit nestlings. Naturwissenschaften 87:460-464

Hõrak P, Surai PF, Møller AP (2002) Fat-soluble antioxidants in the eggs of great tits Parus major in relation to breeding habitat and laying sequence. Avian Sci 2:123-130

Hubálek Z (2004) An annotated checklist of pathogenic microorganisms associated with migratory birds. J Wildl Dis 40:639-659

JMP (2000) JMP. SAS Institute, Cary, NC

> Jones KE, Purvis A (1997) An optimum body size for mammals? Comparative evidence from bats. Funct Ecol 11: 751-756

Koutsos EA, Clifford AJ, Calvert CC, Klasing KC (2003) Maternal carotenoid status modifies the incorporation of dietary carotenoids into immune tissues of growing chickens (Gallus gallus domesticus). J Nutr 133:1132-1138

Lehikoinen E, Sparks TH (2010) Changes in migration. In: Møller AP, Fiedler W, Berthold P (eds) Effects of climate change on birds. Oxford University Press, Oxford, p 89-112

Lehikoinen E, Sparks TH, Zalakevicius M (2004) Arrival and departure dates. In: Møller AP, Fiedler W, Berthold P (eds) Effects of climatic change on birds. Elsevier, Amsterdam, p 1-31

Møller AP (2008) Climate change and micro-geographic variation in laying date. Oecologia 155:848-857

> Møller AP, Erritzøe J (1998) Host immune defence and migration in birds. Evol Ecol 12:945-953

Møller AP, Merilä J (2004) Analysis and interpretation of long-term studies investigating responses to climate change. In: Møller AP, Fiedler W, Berthold P (eds) Effects of climatic change on birds. Elsevier, Amsterdam, p 111-130

Møller AP, Biard C, Blount JD, Ninni P, Saino N, Surai PF (2001) Carotenoid-dependent signals: indicators of foraging efficiency, immunocompetence or detoxification ability? Poultry Avian Biol Rev 11:137-159

Møller AP, de Lope F, Saino N (2004) Parasitism, immunity and arrival date in a migratory bird. Ecology 85:206-219

Møller AP, Mousseau TA, Milinevsky G, Peklo A, Pysanets E, Szép T (2005) Condition, reproduction and survival of barn swallows from Chernobyl. J Anim Ecol 74: 1102-1111

Mountjoy DJ, Leger DW (2001). Vireo song repertoires and migratory distance: three sexual selection hypotheses fail to explain the correlation. Behav Ecol 12:98-102

Mousseau TA, Fox CW (eds) (1998) Maternal effects as adaptations. Oxford University Press, New York, NY

> Ninni P, de Lope F, Saino N, Haussy C, Møller AP (2004) Antioxidants and condition-dependence of arrival date in a migratory passerine. Oikos 105:55-64

> Noseworthy MD, Bray TM (1998) Effect of oxidative stress on brain damage detected by MRI and in vivo P-31NMR. Free Radic Biol Med 24:942-951

Pagel M (1997) Inferring evolutionary processes from phylogenies. Zool Scr 26:331-348

Pagel M (1999) Inferring the historical patterns of biological evolution. Nature 401:877-884

> Paradis E, Baillie SR, Sutherland WJ, Gregory RD (1998) Patterns of natal and breeding dispersal in birds. J Anim Ecol 67:518-536
Pulido F, Berthold P (2004) Microevolutionary response to climate change. In: Møller AP, Fiedler W, Berthold P (eds) Effects of climatic change on birds. Elsevier, Amsterdam, p 151-184

- Pulido F, Berthold P (2010) Current selection for lower migratory activity will drive the evolution of residency in a migratory bird population. Proc Natl Acad Sci USA 107 : 7341-7346

> Purvis A, Rambaut A (1995) Comparative analysis by independent contrasts (CAIC): an Apple Macintosh application for analysing comparative data. Comput Appl Biosci 11:247-251

- Read AF, Weary DM (1992) The evolution of bird song: comparative analyses. Philos Trans R Soc Lond B Biol Sci 338: 165-187

> Rubolini D, Møller AP, Rainio K, Lehikoinen E (2007) Intraspecific consistency and geographic variability in temporal trends of spring migration phenology among European bird species. Clim Res 35:135-146

> Saino N, Bertacche V, Ferrari R, Martinelli R, Møller AP, Stradi R (2002) Carotenoid concentration in barn swallow eggs is influenced by laying order, maternal infection and paternal ornamentation. Proc Biol Sci 269: 1729-1733

Saino N, Ferrari R, Romano M, Martinelli R, Møller AP (2003) Experimental manipulation of egg carotenoids affects immunity of barn swallow nestlings. Proc Biol Sci 270:2485-2489

Saino N, Romano M, Ambrosini R, Ferrari RP, Møller AP (2004) Timing of reproduction and egg quality covary with temperature in the insectivorous barn swallow (Hirundo rustica). Funct Ecol 18:50-57

Sibley CG, Ahlquist JE (1990) Phylogeny and classification of birds. Yale University Press, New Haven, CT

Spottiswoode C, Møller AP (2004) Extra-pair paternity, migration and breeding synchrony in birds. Behav Ecol 15:41-57

Surai PF (2002) Natural antioxidants in avian nutrition and reproduction. Nottingham University Press, Nottingham

> Surai PF, Noble RC, Speake BK (1996) Tissue-specific differences in antioxidant distribution and susceptibility to lipid peroxidation during development of the chick embryo. Biochim Biophys Acta 1304:1-10

Surai PF, MacPherson A, Speake BK, Sparks NHC (2000) Designer egg evaluation in a controlled trial. Eur J Clin Nutr 54:298-305

Tyurin VA, Tyurina YY, Borisenko GG, Sokolova TV and others (2000) Oxidative stress following traumatic brain injury in rats: quantitation of biomarkers and detection of free radical intermediates. J Neurochem 75:2178-2189

Waldenström J, Bensch S, Kiboi S, Hasselquist D, Ottosson U (2002) Cross-species infection of blood parasites between resident and migratory songbirds in Africa. Mol Ecol 11:1545-1554

Welker T, Congleton JL (2005) Oxidative stress in migrating spring Chinook salmon smolts of hatchery origin: changes in vitamin $\mathrm{E}$ and lipid peroxidation. Trans Am Fish Soc 134:1499-1508

> Winkler H, Leisler B, Bernroider G (2004) Ecological constraints on the evolution of avian brains. J Ornithol 145: 238-244 
Appendix. Mean concentrations and information on confounding variables for each of the 14 species and a composite phylogeny

Table A1. Information on number of eggs and clutches analyzed, vitamin A and vitamin E concentrations $( \pm \mathrm{SE})$, change in mean arrival date, body mass, sexual dichromatism (0: sexually monochromatic; 1 : sexually dichromatic), and migration distance. (-) Missing value (only 1 egg available). See 'Materials and methods' for sources

\begin{tabular}{|c|c|c|c|c|c|c|c|c|}
\hline Species & $\begin{array}{l}\text { No. } \\
\text { eggs }\end{array}$ & $\begin{array}{c}\text { No. } \\
\text { clutches }\end{array}$ & $\begin{array}{l}\text { Mean } \\
\text { vitamin A } \\
\left(\mu \mathrm{g} \mathrm{g}^{-1}\right)\end{array}$ & $\begin{array}{l}\text { Mean } \\
\text { vitamin E } \\
\left(\mu g^{-1}\right)\end{array}$ & $\begin{array}{l}\text { Change in } \\
\text { mean arrival } \\
\text { date }\left(\mathrm{d} \mathrm{yr}^{-1}\right)\end{array}$ & $\begin{array}{l}\text { Body } \\
\text { mass } \\
(\mathrm{g})\end{array}$ & $\begin{array}{c}\text { Sexual } \\
\text { dichromatism }\end{array}$ & $\begin{array}{c}\text { Migration } \\
\text { distance } \\
\left({ }^{\circ} \text { latitude }\right)\end{array}$ \\
\hline Acrocephalus palustris & 1 & 1 & $0.61 \pm-$ & $93.44 \pm-$ & -0.157 & 12.00 & 0 & 66.8 \\
\hline Carduelis carduelis & 8 & 2 & $1.94 \pm 0.23$ & $387.57 \pm 31.74$ & -0.368 & 15.60 & 1 & 1.2 \\
\hline Carduelis chloris & 5 & 2 & $1.19 \pm 0.07$ & $174.67 \pm 22.48$ & -0.286 & 27.65 & 1 & 1.3 \\
\hline Corvus corone & 10 & 2 & $2.63 \pm 0.17$ & $104.38 \pm 7.24$ & -0.215 & 544.50 & 0 & 5.7 \\
\hline Delichon urbica & 5 & 2 & $3.19 \pm 0.71$ & $90.73 \pm 10.06$ & 0.026 & 19.55 & 0 & 44.2 \\
\hline Emberiza citrinella & 4 & 1 & $1.47 \pm 0.49$ & $113.22 \pm 36.46$ & -0.205 & 26.75 & 1 & 4.7 \\
\hline Ficedula hypoleuca & 5 & 2 & $1.39 \pm 0.08$ & $109.11 \pm 5.09$ & -0.118 & 14.35 & 1 & 43.0 \\
\hline Hirundo rustica & 5 & 2 & $2.33 \pm 0.44$ & $97.97 \pm 10.02$ & -0.174 & 19.10 & 1 & 42.3 \\
\hline Motacilla alba & 5 & 1 & $1.49 \pm 0.1$ & $70.74 \pm 7.33$ & -0.075 & 20.75 & 1 & 18.1 \\
\hline Parus caeruleus & 100 & 50 & $3.01 \pm 0.62$ & $144.74 \pm 8.74$ & -0.069 & 11.75 & 1 & 0.1 \\
\hline Parus major & 67 & 34 & $2.88 \pm 0.18$ & $137.27 \pm 8.59$ & -0.252 & 18.50 & 1 & 0.1 \\
\hline Troglodytes troglodytes & 2 & 1 & $2.03 \pm 0.11$ & $100.68 \pm 11.78$ & -0.228 & 8.90 & 0 & 1.3 \\
\hline Turdus philomelos & 5 & 1 & $1.68 \pm 0.09$ & $140.29 \pm 15.11$ & -0.192 & 70.50 & 0 & 14.6 \\
\hline Turdus pilaris & 5 & 1 & $1.53 \pm 0.1$ & $55.6 \pm 10.54$ & -0.050 & 92.10 & 0 & 10.8 \\
\hline
\end{tabular}

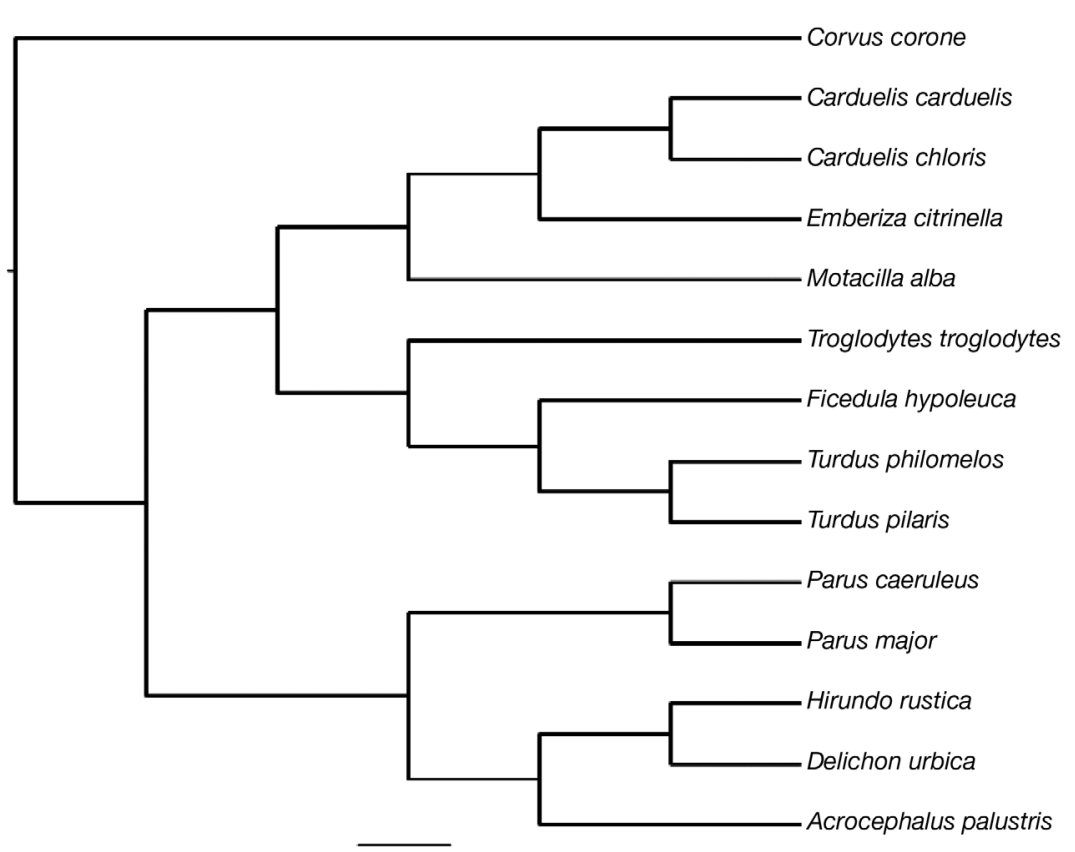

Table A1 corrected after publication. Vitamins A and $\mathrm{E}$ were reversed.

Fig. A1. Phylogenetic relationships between the 14 species used in the comparative analyses. See Section 2 for sources

Editorial responsibility: Nils Chr. Stenseth, Oslo, Norway
Submitted: April 12, 2011; Accepted: July 7, 2011

Proofs received from author(s): October 14, 2011 